\title{
Mid-infrared spectroscopy predictions as indicator traits in breeding programs for enhanced coagulation properties of milk
}

\author{
A. Cecchinato, ${ }^{1}$ M. De Marchi, L. Gallo, G. Bittante, and P. Carnier \\ Department of Animal Science, University of Padova, Viale dell'Università 16, 35020 Legnaro, Padova, Italy
}

\begin{abstract}
The aims of this study were to investigate variation of milk coagulation property (MCP) measures and their predictions obtained by mid-infrared spectroscopy (MIR), to investigate the genetic relationship between measures of MCP and MIR predictions, and to estimate the expected response from a breeding program focusing on the enhancement of MCP using MIR predictions as indicator traits. Individual milk samples were collected from 1,200 Brown Swiss cows (progeny of 50 artificial insemination sires) reared in 30 herds located in northern Italy. Rennet coagulation time (RCT, min) and curd firmness $\left(\mathrm{a}_{30}, \mathrm{~mm}\right)$ were measured using a computerized renneting meter. The MIR data were recorded over the spectral range of 4,000 to $900 \mathrm{~cm}^{-1}$. Prediction models for RCT and $\mathrm{a}_{30}$ based on MIR spectra were developed using partial least squares regression. A cross-validation procedure was carried out. The procedure involved the partition of available data into 2 subsets: a calibration subset and a test subset. The calibration subset was used to develop a calibration equation able to predict individual MCP phenotypes using MIR spectra. The test subset was used to validate the calibration equation and to estimate heritabilities and genetic correlations for measured MCP and their predictions obtained from MIR spectra and the calibration equation. Point estimates of heritability ranged from 0.30 to 0.34 and from 0.22 to 0.24 for RCT and $\mathrm{a}_{30}$, respectively. Heritability estimates for MCP predictions were larger than those obtained for measured MCP. Estimated genetic correlations between measures and predictions of RCT were very high and ranged from 0.91 to 0.96 . Estimates of the genetic correlation between measures and predictions of $\mathrm{a}_{30}$ were large and ranged from 0.71 to 0.87 . Predictions of MCP provided by MIR techniques can be proposed as indicator traits for the genetic enhancement of MCP. The expected response of RCT and $\mathrm{a}_{30}$ ensured by the selection using MIR predictions as indicator traits was equal to or slightly less than the
\end{abstract}

Received March 26, 2009.

Accepted July 6, 2009.

${ }^{1}$ Corresponding author: alessio.cecchinato@unipd.it response achievable through a single measurement of these traits. Breeding strategies for the enhancement of MCP based on MIR predictions as indicator traits could be easily and immediately implemented for dairy cattle populations where routine acquisition of spectra from individual milk samples is already performed.

Key words: milk coagulation property, mid-infrared spectroscopy, heritability, genetic correlation

\section{INTRODUCTION}

The coagulation ability of milk plays an important role in cheese production mainly because of its relationships with cheese yield (Martin et al., 1997; Ikonen et al., 1999; De Marchi et al., 2007) and cheese quality (Ng-Kwai-Hang et al., 1989; Johnson et al., 2001). Good reactivity to rennet, high curd-firming capacity, good syneresis ability, and whey drainage are crucial features of milk for cheese-making. All these characteristics are generally referred to as milk coagulation properties (MCP). Assessment of MCP can be performed through computerized renneting meters, providing measures of rennet coagulation time (RCT, min) and curd firmness $\left(\mathbf{a}_{\mathbf{3 0}}, \mathbf{m m}\right)$, or by using alternative systems based on optical, thermal, mechanical, and vibrational methods, which have been comprehensively reviewed by O'Callaghan et al. (2002). Several studies have reported that exploitable additive genetic variation exists for RCT and $a_{30}$ (Ikonen et al., 1997, 1999; Cassandro et al., 2008) and, thereby, enhancement of these traits through breeding is a viable option. Large-scale recording of individual phenotypes for MCP remains a critical issue because available techniques are time consuming, and high-throughput automated measuring devices are lacking. Because opportunities for breeding based on direct measures of individual MCP phenotypes are limited, optimal selection approaches for enhancing MCP have long been under investigation (Ikonen, 2000; Ikonen et al., 2004; Tyrisevä et al., 2004; Ojala et al., 2005).

Alternative methodologies for testing bovine milk rely on the use of infrared spectroscopy (Laporte et al., 1998; Barbano and Lynch, 2006; Dal Zotto et al., 2008) as in the case of the mid-infrared spectroscopy (MIR). This technology, exhibiting reduced costs of analysis, 
high throughput, and possibilities of large-scale application, is widely used in milk recording programs to predict milk quality traits (e.g., milk protein and fat contents). Calibration equations to predict MCP of bovine milk by MIR spectroscopy have recently been developed, but the accuracy of such predictions seems to be questionable (Dal Zotto et al., 2008; De Marchi et al., 2008). The relevance of MIR predictions as exploitable indicator traits in breeding programs focusing on the enhancement of MCP relies largely on the genetic variation of such predictions and on the magnitude of the genetic correlation between measured and MIRpredicted MCP. No estimates of such parameters are currently available in the literature.

The aims of this study were to investigate, using individual milk samples, variation of MCP measures and their predictions obtained with MIR techniques, to investigate the genetic relationship between measures of MCP and predictions, and to estimate the expected response from a breeding program focusing on the enhancement of MCP using MIR predictions as indicator traits.

\section{MATERIALS AND METHODS}

\section{Sample Collection and MIR Spectra Acquisition}

A total of 1,200 Italian Brown Swiss cows were sampled during the period June 2006 to July 2007. Cows were offspring of $50 \mathrm{AI}$ sires and were reared in 30 herds located in northern Italy. Individual milk samples (1 per animal) were collected during the morning milking of a test day. After collection and with no preservative addition, milk samples were stored in portable refrigerators $\left(4^{\circ} \mathrm{C}\right)$ and transferred to the milk quality lab of Veneto Agricoltura Institute (Thiene, Italy) where RCT and $\mathrm{a}_{30}$ were measured within $3 \mathrm{~h}$ after sample collection.

Mid-infrared spectra were obtained by analyzing 0.25 $\mathrm{mL}$ of milk over the spectral range of 4,000 to $900 \mathrm{~cm}^{-1}$ using a Milko-Scan FT120 equipped with a Fourier transform infrared interferometer (Foss Electric A/S, Hillerød, Denmark). Duplicate spectra were captured for each sample and averaged before data analysis.

\section{Analysis of MCP and Quality Traits of Milk}

Measures of MCP were obtained using a computerized renneting meter (Polo Trade, Monselice, Italy). This measuring device has been widely used to investigate milk coagulation properties (Ikonen et al., 1999, 2004; Ikonen, 2000; De Marchi et al., 2007, 2008; Cassandro et al., 2008). The principle of the computerized renneting meter is based on control of the oscillation, which is driven by an electromagnetic field created by a swinging pendulum immersed in the milk container. A survey system measures differences in the electromagnetic field caused by milk coagulation: the greater the extent of coagulation, the smaller the pendulum swing. The analysis produces a diagram as reported by Dal Zotto et al. (2008).

Milk samples $(10 \mathrm{~mL})$ were heated to $35^{\circ} \mathrm{C}$, and 200 $\mu \mathrm{L}$ of rennet (Hansen standard 190 with $63 \%$ of chymosin and $37 \%$ of pepsin, Pacovis Amrein AG, Bern, Switzerland) diluted to $1.6 \%$ in distilled water was added to milk. Measurement of MCP ended within $31 \mathrm{~min}$ after the addition of the clotting enzyme. This analysis provided measurements of RCT (the time interval in minutes from the addition of the clotting enzyme to the beginning of the coagulation process) and $\mathrm{a}_{30}$ (the width, in millimeters, of the diagram at 31 min after the addition of rennet, which is a measure of curd firmness). Samples that did not coagulate within $31 \mathrm{~min}$ were classified as noncoagulating milk.

In the same laboratory, fat, protein, and casein contents (Combi Foss 6000 FC, Foss Electric A/S), $\mathrm{pH}$, titratable acidity, expressed in Soxhlet-Henkel degrees (Crison Compact D, Crison Instruments SA, Alella, Spain), and SCC (Cell Fossomatic 250, Foss Electric A/S) were determined. Values of SCC were converted by logarithm transformation to SCS [SCS $\left.=3+\log _{2}(\mathrm{SCC} / 100,000)\right]$. Information on cows and herds were provided by the Milk Recording Agencies of Veneto, Italy. Pedigree information was supplied by the Italian Brown Swiss Cattle Breeders Association (ANARB, Verona, Italy) and included all known ancestors of sampled cows.

\section{Statistical Analysis}

Validation Procedure. After the application of editing procedures, which aimed to discard records with errors (e.g., individual identification spectra not matching reference samples) or inconsistent information, data of cows with unknown sire, and records of noncoagulating samples (4\% of total records), 1,033 individual records including measures of MCP and MIR spectra were available for the statistical analysis.

To evaluate the ability of MIR to predict individual MCP phenotypes and the magnitude of the genetic correlation between measures of MCP and their predictions obtained from calibration equations based on MIR spectra, a pseudo-cross-validation procedure was carried out. The procedure involved the partition of available data into 2 subsets: a calibration subset and a test subset. The calibration subset was used to develop a calibration equation able to predict individual MCP phenotypes by using MIR spectra, whereas the test 
subset was used to validate the calibration equation and to estimate heritabilities and the genetic correlation for measured MCP and their predictions obtained from MIR spectra and the calibration equation. Observations (a minimum of 170) to be included in the calibration subset were randomly sampled from the set of available observations with the restriction that at least 5 observations per herd were present in the subset. Records not included in the calibration subset were included in the test subset. The cross-validation procedure was replicated 4 times with the constraint that observations included in the calibration subset of a replicate were not included in the calibration subsets of the other replicates.

Multivariate Data Analysis and Predictive Ability of MIR. The prediction equations were obtained using the Unscrambler software (v.9.6; Camo A/S, Oslo, Norway). Prediction models were developed using partial least squares regression, which is widely used to establish a calibration model and to estimate correlations between reference data and values predicted using spectral data (Hubert and Vanden Branden, 2003). All calibration residuals were then combined to compute the root mean square error of calibration (RMSEC). Models were developed using raw spectra that, for MCP, provided the best performance. For the description of the proficiency of calibration models, the RMSEC and the correlation coefficient of calibration (Downey et al., 2005) were considered. A more detailed description of multivariate data analysis has been reported in De Marchi et al. (2009).

Estimates of (Co)variance Components. For each test subset, estimation of (co)variance components for measures of MCP and their predictions ( $\mathbf{p M C P}$ ) based on calibration equations and MIR spectra were obtained through bivariate Bayesian analyses and linear models. The general form of the linear model, in matrix notation, can be written as follows:

$\left[\begin{array}{l}\mathrm{y}_{1} \\ \mathrm{y}_{2}\end{array}\right]=\left[\begin{array}{cc}\mathrm{X}_{1} & 0 \\ 0 & \mathrm{X}_{2}\end{array}\right] \cdot\left[\begin{array}{l}\beta_{1} \\ \beta_{2}\end{array}\right]+\left[\begin{array}{cc}\mathrm{W}_{1} & \mathbf{0} \\ \mathbf{0} & \mathrm{W}_{2}\end{array}\right] \cdot\left[\begin{array}{l}\mathrm{c}_{1} \\ \mathrm{c}_{2}\end{array}\right]+\left[\begin{array}{cc}\mathrm{z}_{1} & 0 \\ 0 & \mathrm{Z}_{2}\end{array}\right] \cdot\left[\begin{array}{l}\mathrm{a}_{1} \\ \mathrm{a}_{2}\end{array}\right]+\left[\begin{array}{l}\mathrm{e}_{1} \\ \mathrm{e}_{2}\end{array}\right]$,

where $\mathbf{y}_{1}$ and $\mathbf{y}_{2}$ are vectors of MCP observations and pMCP, respectively; $\boldsymbol{\beta}_{1}$ and $\boldsymbol{\beta}_{2}$ are unknown vectors of "fixed" effects; $\mathbf{c}_{1}$ and $\mathbf{c}_{2}$ are unknown vectors of herd effect considered to be normally distributed, $\mathbf{c} \sim N(\mathbf{0}, \mathbf{P} \otimes \mathbf{I})$, where $\mathbf{P}$ is the (co)variance matrix for herd effects; $\mathbf{a}_{1}$ and $\mathbf{a}_{2}$ are unknown vectors of additive genetic effects of animals assumed to follow a multivariate normal distribution $\mathbf{a} \sim N\left(\mathbf{0}, \mathbf{G}_{\mathbf{0}} \otimes \mathbf{A}\right)$, where $\mathbf{G}_{0}$ is the (co)variance matrix for animal effects and $\mathbf{A}$ is the numerator of Wright's relationship matrix; $\mathbf{e}_{1}$ and $\mathbf{e}_{2}$ are vectors of random residuals assumed to follow a normal distribution $\mathbf{e} \sim N\left(\mathbf{0}, \mathbf{R}_{\mathbf{0}} \otimes \mathbf{I}\right)$, where $\mathbf{R}_{0}$ is the residual (co)variance matrix; $\mathbf{X}_{1}$ and $\mathbf{X}_{2}$ are known incidence matrices relating fixed effects in $\boldsymbol{\beta}_{1}$ and $\boldsymbol{\beta}_{2}$ to $\mathbf{y}_{1}$ and $\mathbf{y}_{2}$, respectively; $\mathbf{W}_{1}$ and $\mathbf{W}_{2}$ are known incidence matrices relating herd effects in $\mathbf{c}_{1}$ and $\mathbf{c}_{2}$ to $\mathbf{y}_{1}$ and $\mathbf{y}_{2}$, respectively; and $\mathbf{Z}_{1}$ and $\mathbf{Z}_{2}$ are known incidence matrices relating additive genetic effects in $\mathbf{a}_{1}$ and $\mathbf{a}_{2}$ to $\mathbf{y}_{1}$ and $\mathbf{y}_{2}$, respectively.

The fixed effects included in $\boldsymbol{\beta}_{1}$ and $\boldsymbol{\beta}_{2}$ were DIM classes (class 1: <50 d; class 2: from 50 to $90 \mathrm{~d}$; class 3: from 91 to $120 \mathrm{~d}$; class 4: from 121 to $150 \mathrm{~d}$; class 5: from 151 to $180 \mathrm{~d}$; class 6: from 181 to $220 \mathrm{~d}$; class 7: from 221 to $260 \mathrm{~d}$; class 8: 261 to 300 d; class 9: from 301 to $350 \mathrm{~d}$; and class 10: >350 d) and parity effects (class 1: first parity; class 2: second parity; class 3: third and later parities), respectively.

Flat priors were used for fixed effects and variance components. Marginal posterior distributions of unknown parameters were estimated performing numerical integration by the Gibbs sampler, as implemented in the program TM (available on request from the author at andres.legarra@toulouse.inra.fr). A single chain of 800,000 Gibbs samples was obtained for each bivariate analysis, with a burn-in of 10,000 samples. The effective length of the burn-in period and the chain size were calculated following the methods of Raftery and Lewis (1992) and Geyer (1992), respectively. Samples were saved every 200 iterations. The posterior median was used as a point estimate of (co)variance components and related parameters. Lower and upper bounds of the symmetric $95 \%$ probability density regions for heritability $\left(\mathrm{h}^{2}\right)$ and additive genetic correlation $\left(\mathrm{r}_{\mathrm{A}}\right)$ were obtained from the estimated marginal densities.

Heritabilities were computed as

$$
\mathrm{h}^{2}=\frac{\sigma_{\mathrm{A}}^{2}}{\sigma_{\mathrm{A}}^{2}+\sigma_{\mathrm{H}}^{2}+\sigma_{\mathrm{E}}^{2}},
$$

where $\sigma_{\mathrm{A}}^{2}, \sigma_{\mathrm{H}}^{2}$, and $\sigma_{\mathrm{E}}^{2}$ are the additive genetic, herd, and residual variances, respectively.

Genetic correlations were computed as

$$
\mathrm{r}_{\mathrm{A}}=\frac{\sigma_{\mathrm{MCP}, \mathrm{pMCP}}}{\sigma_{\mathrm{MCP}} \sigma_{\mathrm{pMCP}}},
$$

where $\sigma_{\mathrm{MCP}, \mathrm{pMCP}}$ is the additive genetic covariance between measures and MIR predictions of RCT $\left(\mathrm{a}_{30}\right)$ and $\sigma_{\mathrm{MCP}}$ and $\sigma_{\mathrm{pMCP}}$ are the additive genetic standard deviations for measures and MIR predictions of RCT $\left(\mathrm{a}_{30}\right)$, respectively. 


\section{Breeding Program}

A closed nucleus dairy cattle population with overlapping generations was simulated using SelAction (Rutten et al., 2002) to compare predicted selection responses when direct measures or MIR predictions of coagulation properties were available as sources of information for a pseudo-BLUP selection index (Bijma et al., 2001). With 2 sexes and a maximum age of $10 \mathrm{yr}$ for both sexes, there were 20 age classes (10 classes per each sex), and the time difference between 2 consecutive classes was 1 yr. Culling was assumed to occur randomly at a rate equal to $10 \%$ of candidates for all age classes. Each year, 10 sires and 200 dams were selected to be parents of new animals. The number of breeding candidates selected from each age class was determined by truncation selection on pseudo-BLUP indices across age classes. Parents could not be selected from age class 1 because individuals of that class were not reproductive yet. Each selected male was mated at random to 20 dams and, because female fertility was $80 \%$, each dam produced 0.8 offspring ( 0.4 per each sex on average). The breeding scheme used a conventional progeny-testing program and reproductive technologies different from AI (e.g., superovulation and embryo transfer) were not employed. Young bulls were progeny-tested by generating 100 daughters per bull through matings with cows randomly sampled outside the nucleus. The first lactation of all daughters of tested bulls was recorded and provided the phenotypic information used to estimate breeding values of young bulls. Genetic evaluation of females was mostly based on their own phenotypic information recorded during the first lactation. For individuals in age class 1 and 2, sources of information for the pseudo-BLUP selection index for animal $i$ were the EBV of the sire and of the dam. When cows were 3 yr old, their phenotypic data became available and were an additional source of information for the index of those animals, but also for the index of their male and female half-sibs. Availability of progeny information occurred when bulls were 5 yr old. Selection indices for females were not updated with any progeny information or with additional phenotypic information recorded in the second and later lactations of cows.

\section{Prediction of Selection Responses}

The prediction of selection responses considered 2 alternatives with the same breeding goal, which included MCP only. In alternative 1 , it was assumed that the phenotypic information recorded in the first lactation of all cows was, for difficulties related to large-scale recording of individual MCP phenotypes, a single mea- sure of RCT and $\mathrm{a}_{30}$. In alternative 2 , MIR spectra were obtained for all cows and used to predict individual MCP phenotypes by analyzing up to 6 milk samples collected during the first lactation. Mid-infrared spectroscopy predictions of MCP were then used as sources of information in the construction of the index used to select breeding candidates in the simulated population. Because no information on repeatability of MIR predictions was available, the expected responses were computed by assuming that the repeatability of MIR predictions ranged from 0.4 to 0.9 . The number of MIR predictions of MCP available per cow ranged from 1 to 6 , and the values used for variances, heritabilities, and correlations were averages of estimates obtained in this study. Because heritability did not vary in our simulation, different values of repeatability of MIR predictions were simply the outcome of a changed ratio in permanent and temporary environmental variance.

\section{RESULTS AND DISCUSSION}

\section{Descriptive Statistics}

Descriptive statistics for MCP, milk yield, and milk quality traits are reported in Table 1. Milk yield averaged $28.6 \mathrm{~kg} / \mathrm{d}$. Somatic cell score had the largest coefficient of variation $(\mathrm{CV})$, whereas $\mathrm{pH}$ had the smallest. Measures of MCP were very variable (RCT: $\mathrm{CV}=$ $\left.0.27 ; \mathrm{a}_{30}: \mathrm{CV}=0.21\right)$, facilitating the development of calibration equations based on MIR spectra. Average values for RCT and $\mathrm{a}_{30}$ were $15 \mathrm{~min}$ and $41.7 \mathrm{~mm}$, respectively. These values are close to recommended values in practical cheese making by Zannoni and Annibaldi (1981) and similar to those reported by Mariani et al. (1997) for Brown Swiss cattle. The RCT and $\mathrm{a}_{30}$ values observed in this study are indicative of faster coagulation rates and better results of the curd-firming process compared with those reported by Cassandro et al. (2008) for individual milk samples of HolsteinFriesian cows and the difference was similar to those reported for bulk milk (De Marchi et al., 2008).

\section{Predictions of Coagulation Properties}

Descriptive statistics for calibration and test subsets of data are presented in Table 2. Means and CV of $\mathrm{RCT}$ and $\mathrm{a}_{30}$ of calibration sets were comparable among the 4 subsets and with total data. The RMSEC ranged between 2.15 and $2.63 \mathrm{~min}$ and between 5.72 and 6.58 $\mathrm{mm}$ for RCT and $\mathrm{a}_{30}$, respectively. As suggested by Williams (2003), the coefficient of determination $\left(\mathrm{R}^{2}\right)$ of each model allows the evaluation of the accuracy of the predictions; the RCT models $\left(\mathrm{R}^{2}\right.$ from 0.61 to 0.69$)$ allowed for the discrimination between large and small 
Table 1. Descriptive statistics $(n=1,033)$ of milk coagulation properties, milk yield, and milk quality traits

\begin{tabular}{lcccc}
\hline Trait $^{1}$ & Mean & CV, \% & Minimum & Maximum \\
\hline Milk yield, kg/d & 28.6 & 28 & 7.4 & 68.0 \\
DIM, d & 202 & 62 & 6 & 597 \\
Milk fat, \% & 3.98 & 19 & 0.88 & 6.99 \\
Milk protein, \% & 3.72 & 10 & 2.68 & 5.41 \\
Casein, \% & 2.88 & 10 & 1.98 & 4.16 \\
Casein index, \% & 78 & 3 & 58 & 90 \\
SCS & 2.41 & 90 & -4.55 & 8.73 \\
pH & 6.69 & 2 & 3.59 & 7.20 \\
Titratable acidity, $\mathrm{SH}^{\circ} / 50 \mathrm{~mL}$ & 3.25 & 13 & 0.85 & 4.77 \\
RCT, min & 15.0 & 27 & 2.0 & 29.3 \\
a $_{30}$ mm & 41.7 & 21 & 6.0 & 64.0 \\
\hline
\end{tabular}

${ }^{1} \mathrm{SH}^{\circ}=$ Soxhlet-Henkel degrees; $\mathrm{SCS}=\log _{2}(\mathrm{SCC} / 100,000)+3 ; \mathrm{RCT}=$ rennet coagulation time for milk that coagulated; $\mathrm{a}_{30}=$ curd firmness for milk that coagulated.

$\mathrm{RCT}$ values, whereas the $\mathrm{a}_{30}$ models $\left(\mathrm{R}^{2}\right.$ from 0.46 to 0.52 ) did not allow this discrimination. The molecular basis for the prediction of MCP was investigated and highlights the importance of the protein and lipid regions of the MIR spectra in predicting MCP of individual milk samples (De Marchi et al., 2009). Means and $\mathrm{CV}$ of the 4 calibration sets were consistent with those of the test subsets.

Results on the reliability of models based on MIR spectra for the prediction of RCT and $\mathrm{a}_{30}$ reported in this study are consistent with those reported by Dal Zotto et al. (2008) and De Marchi et al. (2009) in a preliminary investigation on the potential of MIR as a predictive tool for MCP.

\section{Variance Components and Heritability}

Point estimates (median of the marginal posterior density of the parameter) for the additive genetic, herd, and residual variances and heritabilities of MCP mea- sured by a computerized renneting meter and predicted by MIR (pMCP) for each subset of the data are reported in Table 3. The additive genetic variance for measured MCP ranged from 4.40 to $5.48 \mathrm{~min}^{2}$ for RCT and from 18.11 to $22.2 \mathrm{~mm}^{2}$ for $\mathrm{a}_{30}$. The additive genetic variances for pMCP were slightly lower than those estimated for measured MCP and varied across subsets of data from 3.18 to $4.12 \mathrm{~min}^{2}$ for RCT and from 12.19 to $22.24 \mathrm{~mm}^{2}$ for $\mathrm{a}_{30}$. Estimates of genetic variances for measures of $\mathrm{RCT}$ and $\mathrm{a}_{30}$ are comparable with those reported by Cassandro et al. (2008) for Italian Holstein-Friesian cows. The large additive genetic variance estimated for MCP and pMCP suggests possible exploitation of such variation in breeding programs for dairy cattle aiming for genetic improvement of milk coagulation ability. Direct selection for MCP might be the most effective selection strategy, but population-wide recording of individual phenotypes for MCP is not applicable because of limitations imposed by features of computerized renneting meters. Although EBV for MCP have

Table 2. Descriptive statistics for rennet coagulation time (RCT) and curd firmness $\left(\mathrm{a}_{30}\right)$ for each subset of data ${ }^{1}$

\begin{tabular}{|c|c|c|c|c|c|c|c|c|c|c|c|c|}
\hline Item & \multicolumn{7}{|c|}{ Calibration set } & \multicolumn{5}{|c|}{ Test set } \\
\hline \multicolumn{13}{|l|}{$\mathrm{RCT}, \min$} \\
\hline Subset 1 & 171 & 15.1 & 27 & 8.3 & 29.5 & 0.61 & 2.3 & 862 & 14.9 & 26 & 3.2 & 29.3 \\
\hline Subset 2 & 170 & 15.2 & 27 & 7.5 & 27.0 & 0.61 & 2.6 & 863 & 14.9 & 26 & 3.2 & 29.3 \\
\hline Subset 3 & 175 & 14.8 & 26 & 8.2 & 29.0 & 0.69 & 2.2 & 858 & 14.9 & 25 & 3.2 & 29.3 \\
\hline Subset 4 & 171 & 15.3 & 28 & 3.2 & 29.6 & 0.64 & 2.5 & 862 & 14.9 & 25 & 7.5 & 29.2 \\
\hline Subset 2 & 170 & 40.8 & 20 & 12 & 59 & 0.52 & 5.7 & 863 & 41.9 & 21 & 6 & 64 \\
\hline Subset 3 & 175 & 41.8 & 20 & 21 & 64 & 0.46 & 6.1 & 858 & 41.7 & 21 & 6 & 64 \\
\hline Subset 4 & 171 & 41.5 & 22 & 6 & 59 & 0.49 & 6.6 & 862 & 41.7 & 20 & 8 & 64 \\
\hline
\end{tabular}

${ }^{1}$ Calibration set $=$ samples used to develop a calibration equation to predict individual RCT and $\mathrm{a}_{30}$ phenotypes using mid-infrared (MIR) spectra; test set $=$ samples used to validate the calibration equation and to estimate heritabilities and the genetic correlation for measured RCT and $\mathrm{a}_{30}$ and their predictions obtained from MIR spectra and calibration equation. Subsets 1, 2, 3, and 4 are subsets of data used to validate the calibration equations and to estimate genetic parameters for measures of coagulation properties and their predictions obtained from MIR spectra and calibration equations.

${ }^{2}$ Root mean square error of calibration. 
Table 3. Posterior median (SD) for additive genetic $\left(\sigma_{\mathrm{A}}^{2}\right)$, herd $\left(\sigma_{\mathrm{H}}^{2}\right)$ and residual variance $\left(\sigma_{\mathrm{E}}^{2}\right)$ and heritabilities $\left(\mathrm{h}^{2}\right)$ for measures and predictions by mid-infrared spectroscopy (MIR) of rennet coagulation time (RCT) and curd firmness $\left(\mathrm{a}_{30}\right)$

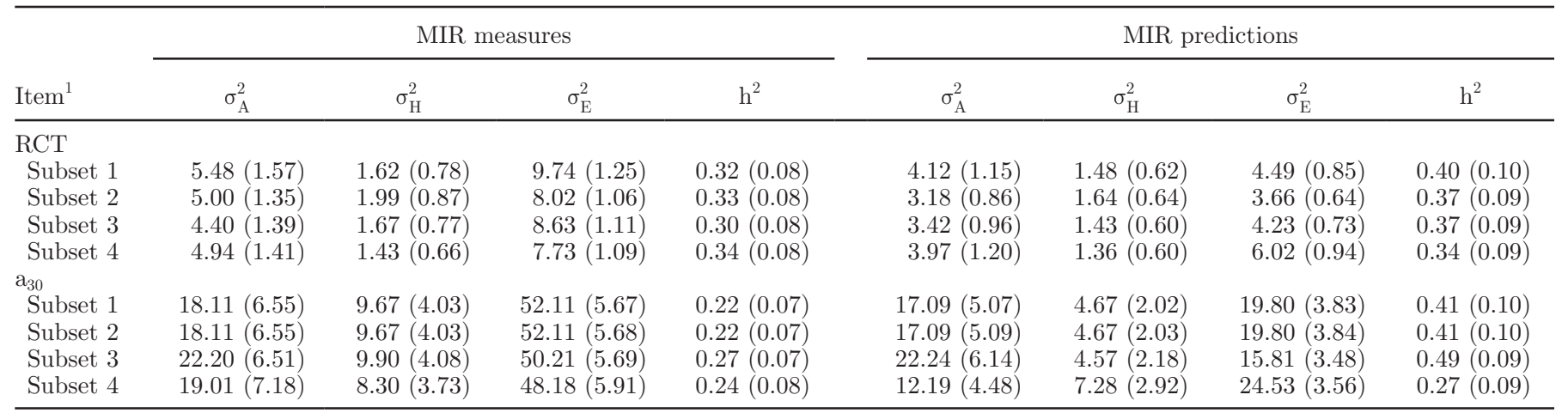

${ }^{1}$ Subsets $1,2,3$, and 4 are subsets of data used to validate the calibration equations and to estimate genetic parameters for measures of coagulation properties and their predictions obtained from MIR spectra and calibration equations.

been obtained from direct measures of phenotypes in experimental studies (Ikonen, 2000; Cassandro et al., 2008), selection strategies based on direct measures of MCP would be very hard to implement. High throughput (potentially, hundreds of samples per hour), ease of use, and reduced cost of analysis make MIR technology a promising alternative for the assessment of MCP at the population level.

Estimates of variance due to herd effects on MCP measures ranged from 1.43 to $1.99 \mathrm{~min}^{2}$ for RCT and from 8.30 to $9.90 \mathrm{~mm}^{2}$ for $\mathrm{a}_{30}$. Compared with measures, MIR predictions of these traits exhibited a slight and a marked decrease in the estimated variances for RCT and $\mathrm{a}_{30}$, respectively. For $\mathrm{a}_{30}$, the estimated herd variance of MIR predictions was lower than $50 \%$ of the estimated herd variance obtained for $\mathrm{a}_{30}$ measures in all subsets of data with the exception of subset 4 . No estimates of variance due to herd effects on MCP or of proportion of herd variance to total variance are currently available in the literature for comparison. However, Ikonen et al. (1999) observed a considerable variation for MCP across herds in bulk milk samples. In addition, results from studies dealing with factors that vary across herds exist. Some studies emphasized the importance of dietary energy levels on variation of MCP (Macheboeuf et al., 1993; Kreuzer et al., 1996) and of cheese yield and quality (Kefford et al., 1995).

Point estimates of heritability for MCP traits were larger for RCT (from 0.30 to 0.34 ) than for $\mathrm{a}_{30}$ (from 0.22 to 0.24 ) and were consistent with estimates reported by other studies for Ayrshire and Holstein-Friesian cattle populations (Ikonen et al., 1999; Tyrisevä et al., 2004; Cassandro et al., 2008), but lower than estimates reported for Ayrshire cattle by Lindström et al. (1984) and Ikonen et al. (2004) or by von Oloffs et al. (1992) for Angler cows. Differences in breeds and statistical models might explain some of these inconsistencies. The estimated heritability for $\mathrm{a}_{30}$ measures obtained in this study were similar to those obtained by Tyrisevä et al. (2004) from a sample of Finnish Ayrshire and HolsteinFriesian cows but lower than estimates reported by other authors. von Oloffs et al. (1992) reported estimates of heritability for $\mathrm{a}_{30}$ ranging from 0.30 (Holstein-Friesian) to 0.39 (Angler). Ikonen et al. (1999) estimated a heritability value of 0.40 for $\mathrm{a}_{30}$ from a sample of Finnish Ayrshire and Holstein-Friesian, whereas in a study on Ayrshire cows, Ikonen et al. (2004) obtained estimates of heritability for $\mathrm{a}_{30}$ ranging from 0.22 to 0.39 . The estimates of heritability for measures of MCP traits were larger than those obtained for some traits that are already included in the current breeding goal for the Italian Brown cattle population and offer an opportunity of being exploited in selection programs aiming at MCP enhancement.

Heritability estimates for pMCP were larger than those obtained for measured MCP. For MIR-predicted $\mathrm{RCT}$, the estimated heritability ranged from 0.34 to 0.40 and, for predictions of $\mathrm{a}_{30}$, from 0.27 to 0.49 . Heritability differences between MCP predictions and measures are largely attributable to changes in the magnitude of the estimated residual variance. Although all estimated variances for MIR-predicted data were smaller than those for measured MCP, the relative decreases were smaller for additive genetic variance than for the residual variance. The decrease in the herd variance estimate obtained for MIR predictions compared with measures was large for $\mathrm{a}_{30}$ only. For $\mathrm{a}_{30}$, the difference between heritability estimates obtained for MIR predictions and for measures was larger than for RCT because of smaller and larger differences in the estimated variance for genetic and nongenetic effects, respectively. 
Table 4. Posterior median, $\mathrm{SD}$, and symmetric $95 \%$ posterior density region (PDR95\%) for additive genetic ( $\left.\mathrm{r}_{\mathrm{A}}\right)$ and phenotypic $\left(\mathrm{r}_{\mathrm{P}}\right)$ correlations between measures of rennet coagulation time and curd firmness and their predictions by mid-infrared spectroscopy (MIR)

\begin{tabular}{|c|c|c|c|c|c|c|}
\hline Subset 1 & 0.91 & 0.07 & 0.70 to 0.99 & 0.67 & 0.02 & 0.61 to 0.71 \\
\hline Subset 2 & 0.93 & 0.06 & 0.75 to 0.99 & 0.61 & 0.03 & 0.55 to 0.67 \\
\hline Subset 3 & 0.91 & 0.06 & 0.72 to 0.98 & 0.72 & 0.02 & 0.67 to 0.77 \\
\hline Subset 4 & 0.96 & 0.03 & 0.85 to 0.99 & 0.69 & 0.02 & 0.64 to 0.74 \\
\hline Subset 2 & 0.74 & 0.15 & 0.35 to 0.94 & 0.51 & 0.03 & 0.44 to 0.57 \\
\hline Subset 3 & 0.77 & 0.16 & 0.34 to 0.95 & 0.48 & 0.04 & 0.39 to 0.55 \\
\hline Subset 4 & 0.87 & 0.11 & 0.58 to 0.97 & 0.54 & 0.03 & 0.37 to 0.58 \\
\hline
\end{tabular}

${ }^{1} \mathrm{RCT}=$ rennet coagulation time measured by a computerized renneting meter; $\mathrm{pRCT}=$ rennet coagulation time predicted by calibration equations using MIR spectra; $\mathrm{a}_{30}=$ curd firmness measured by a computerized renneting meter; $\mathrm{pa}_{30}=$ curd firmness predicted by calibration equations using MIR spectra. Subsets 1, 2, 3, and 4 are subsets of data used to validate the calibration equations and to estimate genetic parameters for measures of coagulation properties and their predictions obtained from MIR spectra and calibration equations.

\section{Correlations Between Measures and MIR Predictions of MCP}

Point estimates (posterior medians), standard deviations, and symmetric $95 \%$ posterior density intervals for additive genetic $\left(\mathrm{r}_{\mathrm{A}}\right)$ and phenotypic $\left(\mathrm{r}_{\mathrm{P}}\right)$ correlations between measures of MCP and their predictions by MIR are reported in Table 4 . The estimated genetic correlations between measures and predictions of RCT were very large and ranged from 0.91 to 0.96 , whereas the phenotypic correlations were smaller (0.67 to 0.72 ). Estimates of the genetic correlation between measures and predictions of $\mathrm{a}_{30}$ were also large (0.71 to 0.87), and greater than the phenotypic correlations (0.48 to $0.54)$.

The estimated posterior densities of the genetic correlations between measures and MIR predictions of MCP are depicted in Figure 1. The posterior densities were skewed and their shape was similar across subsets of data with the exception of densities estimated using subset 4 . These densities exhibited a smaller degree of dispersion than those obtained from the analysis of subsets 1,2 , and 3 . The posterior densities of the genetic correlations between measures and MIR predictions for $\mathrm{a}_{30}$ were more dispersed than for RCT, indicating more uncertainty in the estimation of these parameters for $\mathrm{a}_{30}$ than for RCT. For RCT, the estimated symmetric $95 \%$ posterior density region indicated that, in the most unfavorable situation (subset 1), the genetic correlation between measures and MIR predictions had a $97.5 \%$ posterior probability of being greater than 0.7 . The inferior bound of the estimated symmetric $95 \%$ posterior density interval of the genetic correlation between measures and predictions of $\mathrm{a}_{30}$ was much smaller than for RCT, but, also for this trait, the interval did not include zero. These results support the role of MIR

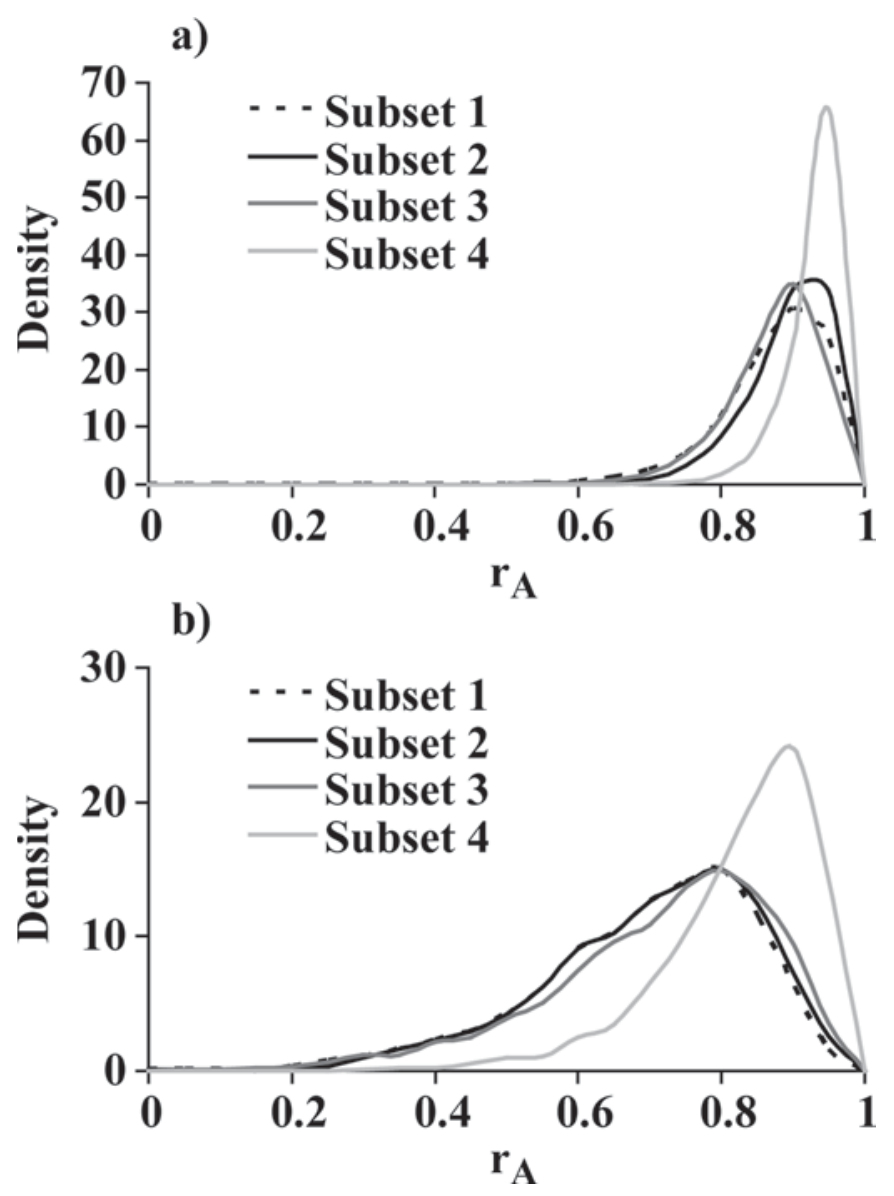

Figure 1. Marginal posterior distributions of the additive genetic correlation $\left(\mathrm{r}_{\mathrm{A}}\right)$ between measures obtained with a computerized renneting meter and their predictions provided by mid-infrared (MIR) spectroscopy for a) rennet coagulation time or b) curd firmness. Subsets 1,2,3, and 4 are subsets of data used to validate the calibration equations and to estimate genetic parameters for measures of coagulation properties and their predictions obtained from MIR spectra and calibration equations. 
Subset 1

a)

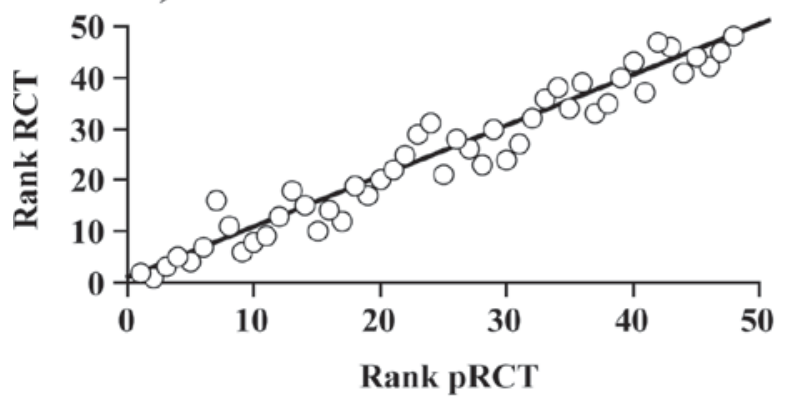

Subset 2

a)

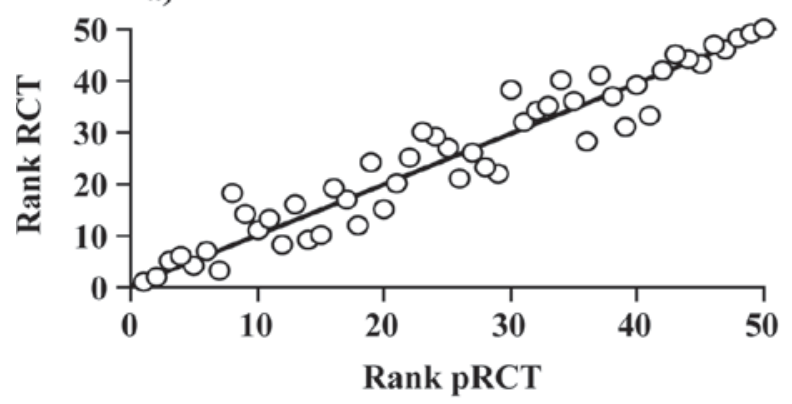

Subset 3

a)

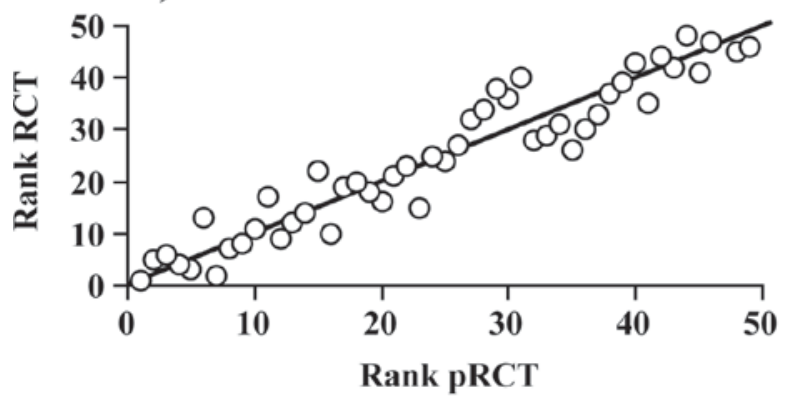

Subset 4

a)

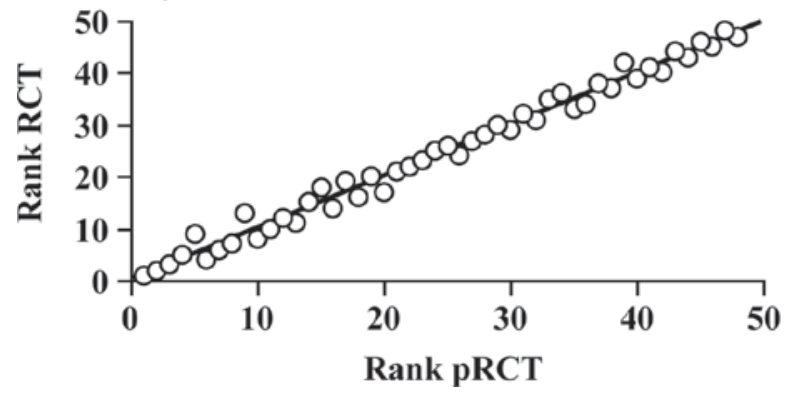

b)

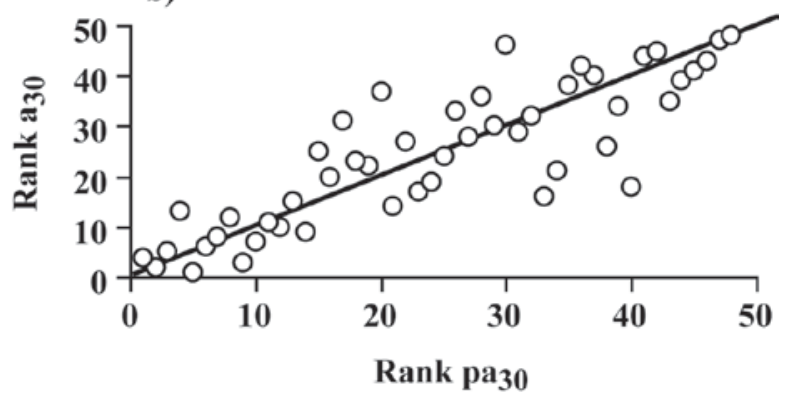

b)

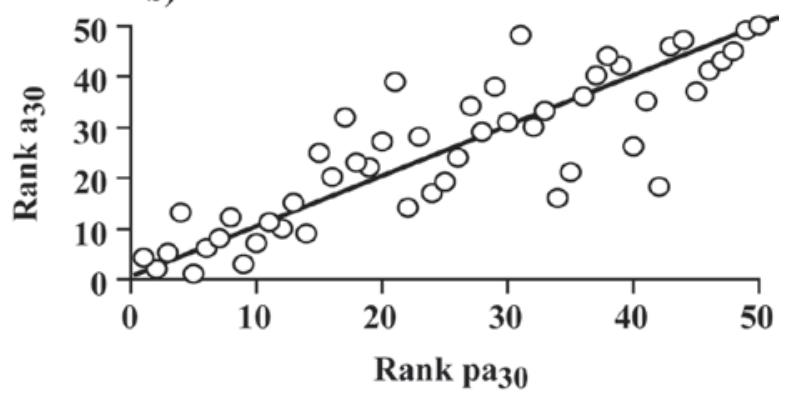

b)

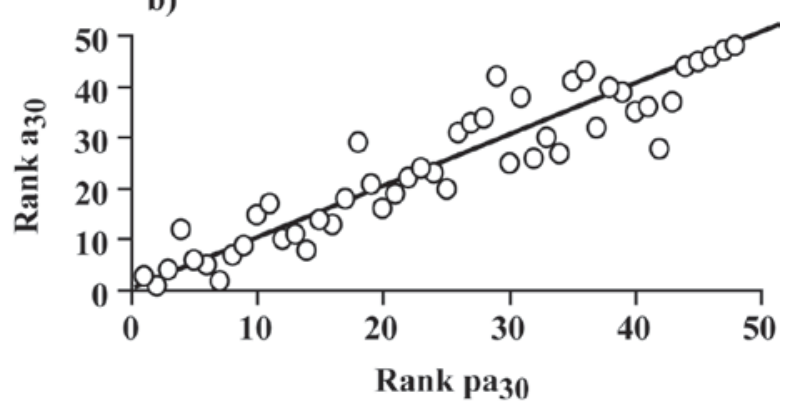

b)

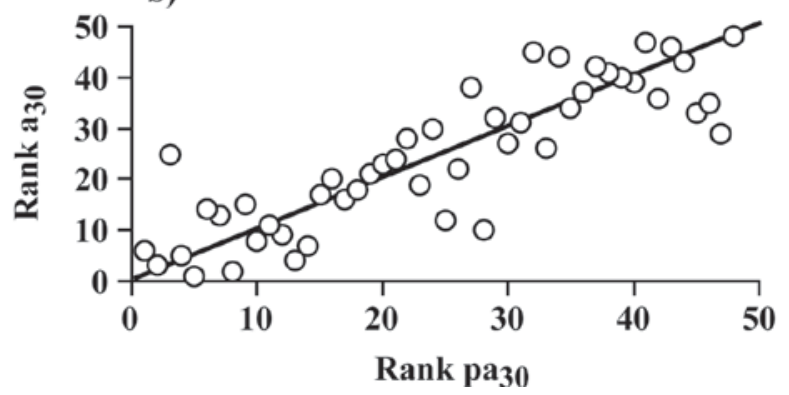

Figure 2. Relationships between sire rankings based on EBV for measures and predictions by mid-infrared (MIR) spectroscopy for a) rennet coagulation time or b) curd firmness for each subset of the data. RCT = rennet coagulation time measured by a computerized renneting meter; $\mathrm{pRCT}=$ rennet coagulation time predicted by calibration equations using MIR spectra; $\mathrm{a}_{30}=$ curd firmness measured by a computerized renneting meter; $\mathrm{pa}_{30}=$ curd firmness predicted by calibration equations using MIR spectra. Subsets 1, 2, 3, and 4 are subsets of data used to validate the calibration equations and to estimate genetic parameters for measures of coagulation properties and their predictions obtained from MIR spectra and calibration equations. Subset $1=\operatorname{sires}(\mathrm{n}=48)$ with at least 3 daughters $($ mean $=16$; minimum $=3 ;$ maximum $=65)$; subset $2=$ sires $(\mathrm{n}=50)$ with at least 3 daughters $($ mean $=16$; minimum $=3$; maximum $=62)$; subset $3=\operatorname{sires}(\mathrm{n}=49)$ with at least 3 daughters $($ mean $=16 ;$ minimum $=3 ;$ maximum $=65)$; subset $4=\operatorname{sires}(\mathrm{n}=49)$ with at least 3 daughters $($ mean $=16 ;$ minimum $=3 ;$ maximum $=64)$. 
Table 5. Predicted response $(\Delta)$ of milk coagulation properties to selection based on mid-infrared spectroscopy (MIR) predictions as indicator traits for rennet coagulation time (RCT) and curd firmness $\left(\mathrm{a}_{30}\right)^{1}$

\begin{tabular}{lcrc}
\hline $\begin{array}{l}\text { Repeatability of } \\
\text { MIR predictions }\end{array}$ & $\mathrm{n}^{2}$ & $\Delta \mathrm{RCT}, \%$ & $\Delta \mathrm{a}_{30}, \%$ \\
\hline 0.4 & 1 & 94.05 & 80.72 \\
& 2 & 97.14 & 83.33 \\
& 4 & 99.76 & 85.57 \\
0.5 & 6 & 100.71 & 86.57 \\
& 1 & 94.05 & 80.72 \\
& 2 & 96.67 & 82.83 \\
0.6 & 4 & 98.33 & 84.33 \\
& 6 & 99.05 & 84.95 \\
& 1 & 94.05 & 80.72 \\
0.7 & 2 & 95.95 & 82.21 \\
& 4 & 97.14 & 83.33 \\
& 6 & 97.62 & 83.71 \\
0.8 & 1 & 94.05 & 80.72 \\
& 2 & 95.48 & 81.84 \\
& 4 & 96.43 & 82.46 \\
0.9 & 6 & 96.70 & 82.83 \\
& 1 & 94.05 & 80.72 \\
& 2 & 95.00 & 81.34 \\
& 4 & 95.48 & 81.84 \\
& 6 & 95.71 & 81.96 \\
& 1 & 94.05 & 80.72 \\
& 2 & 94.52 & 80.97 \\
& 4 & 94.76 & 81.22 \\
& 6 & 94.76 & 81.22 \\
\hline
\end{tabular}

${ }^{1}$ Predicted responses are expressed as fractions of the expected response to direct selection for enhanced milk coagulation properties based on a single measurement of RCT $(\Delta \mathrm{RCT}=-0.420 \mathrm{~min} / \mathrm{yr})$ or $\mathrm{a}_{30}\left(\Delta \mathrm{a}_{30}=0.804 \mathrm{~mm} / \mathrm{yr}\right)$.

${ }^{2}$ Number of MIR predictions available in the first lactation of cows.

predictions as indicator traits for $\mathrm{MCP}$ in breeding programs aiming to enhance coagulation properties of milk.

The relationships between sire rankings based on EBV for measures and for MIR predictions of MCP are depicted in Figure 2. The correlations between sire EBV based on measures and prediction of RCT ranged from 0.96 to 0.99 , whereas the range of the same correlations for $\mathrm{a}_{30}$ was from 0.85 to 0.93 . As detectable from inspection of Figure 2, changes in sire rankings due to the use, as ranking criterion, of EBV for MIR predictions instead of those for MCP measures were limited and occurred most often at intermediate rank positions.

\section{Response to Selection for Enhanced Coagulation Properties}

Expected responses to selection for enhanced coagulation properties of milk based on MIR predictions as indicator traits are presented in Table 5. The deterministic simulation considered a single-trait breeding goal and selection aimed to enhance only RCT or only $\mathrm{a}_{30}$. Direct selection for enhanced MCP was based on a single phenotypic measure collected during the first lactation of cows. This was because of difficulties related to large-scale recording of these traits with computerized renneting meters, which make the recording of repeated measures per cow unfeasible or too expensive. The response to direct selection for these traits was $-0.420 \mathrm{~min} / \mathrm{yr}$ and $0.804 \mathrm{~mm} / \mathrm{yr}$ (data not reported in table) for RCT and $\mathrm{a}_{30}$, respectively. When selection for enhanced MCP was based on a single MIR prediction of those traits, the predicted response was 94.05 and $80.72 \%$ for $\mathrm{RCT}$ and $\mathrm{a}_{30}$, respectively, of the response to selection based on a single measure of these traits. In current milk recording programs, availability of repeated MIR predictions of MCP would be easily attainable because, in many countries, MIR techniques have already been implemented to predict protein and fat contents of individual milk samples, and collection of individual milk samples during lactation is carried out more than once. When predicting selection responses, we assumed a large range of variation of the repeatability (rp) of MIR predictions. Because heritability of MIR predictions was held constant, variation of $\mathrm{rp}$ was obtained by varying the ratio of permanent environmental to temporary environmental variance. As a result, situations with a single measurement gave a constant response, even though a decrease of response with decreased repeatability might be expected. This is because heritability decreases when absolute total environmental variance increases at constant genetic variance. In the most favorable situation (i.e., $\mathrm{rp}=0.4$ and availability of $6 \mathrm{MIR}$ predictions), the expected response obtained using MIR predictions was, for RCT, slightly greater than the response ensured by selection using a single measures of RCT. For $\mathrm{a}_{30}$, using MIR predictions instead of a single measure of the trait caused a limited decrease $(-13.6 \%)$ in the selection response. As expected, the increase of the response due to the use of multiple MIR predictions of MCP was small when the repeatability of MIR prediction increased.

\section{CONCLUSIONS}

Predictions of MCP provided by MIR techniques can be proposed as indicator traits when breeding for enhanced coagulation properties of milk is of interest. The genetic response in RCT and $\mathrm{a}_{30}$ ensured by the selection using MIR predictions as indicator traits is expected to be equal to or slightly lower than the response achievable through direct measurement of the traits. Breeding strategies for the enhancement of MCP could be easily and immediately implemented for dairy cattle populations in which routine acquisition of spectra from individual milk samples is already performed. Studies on the genetic relationships between MCP 
predictions and traits included in the current breeding goal of dairy cattle populations will be the matter of future studies.

\section{ACKNOWLEDGMENTS}

The authors acknowledge the Italian Ministry of University and Research for financial support (PRIN2005prot. 2005074889_002). The authors gratefully acknowledge the Provincial Breeders Associations of Treviso, Venezia, Vicenza, and Padova, and the Italian Brown Swiss Cattle Breeders Association (ANARB) for having provided milk recording and pedigree data, and the lab of Veneto Agricoltura (Thiene, Italy) for milk analyses. The support by Trento province and Superbrown Consortium of Bolzano and Trento is also acknowledged. The authors also acknowledge E. López de Maturana for the use of the TM program.

\section{REFERENCES}

Barbano, D. M., and J. M. Lynch. 2006. Major advances in testing of dairy products: Milk component and dairy product attribute testing. J. Dairy Sci. 89:1189-1194.

Bijma, P., J. A. M. Van Arendonk, and J. A. Woolliams. 2001. Predicting rates of inbreeding for livestock improvement schemes. J. Anim. Sci. 79:840-853.

Cassandro, M., A. Comin, M. Ojala, R. Dal Zotto, M. De Marchi, L. Gallo, P. Carnier, and G. Bittante. 2008. Genetic parameters for milk coagulation properties and their relationships with milk yield and quality traits in Italian Holstein cows. J. Dairy Sci. 91:371-376.

Dal Zotto, R., M. De Marchi, A. Cecchinato, M. Penasa, M. Cassandro, P. Carnier, L. Gallo, and G. Bittante. 2008. Reproducibility and repeatability of measures of milk coagulation properties and predictive ability of mid-infrared reflectance spectroscopy. J. Dairy Sci. 91:4103-4112.

De Marchi, M., G. Bittante, R. Dal Zotto, C. Dalvit, and M. Cassandro. 2008. Effect of Holstein Friesian and Brown Swiss breeds on quality of milk and cheese. J. Dairy Sci. 91:4092-4102.

De Marchi, M., R. Dal Zotto, M. Cassandro, and G. Bittante. 2007. Milk coagulation ability of five dairy cattle breeds. J. Dairy Sci. 90:3986-3992.

De Marchi, M., C. C. Fagan, C. P. O'Donnell, A. Cecchinato, R. Dal Zotto, M. Cassandro, M. Penasa, and G. Bittante. 2009. Prediction of coagulation properties, titrable acidity, and $\mathrm{pH}$ of bovine milk using mid-infrared spectroscopy. J. Dairy Sci. 92:423-432.

Downey, G., E. Sheehan, C. Delahunty, D. O'Callaghan, T. Guinee, and V. Howard. 2005. Prediction of maturity and sensory attributes of Cheddar cheese using near infrared spectroscopy. Int. Dairy J. 15:701-709.

Geyer, C. J. 1992. Practical Markov chain Monte Carlo. Stat. Sci. $7: 473-511$.

Hubert, M., and K. Vanden Branden. 2003. Robust methods for partial least squares regression. J. Chemometr. 17:537-549.

Ikonen, T. 2000. Possibilities of genetic improvement of milk coagulation properties of dairy cows. PhD Diss. Univ. Helsinki, Finland. http://ethesis.helsinki.fi/julkaisut/maa/kotie/vk/ikonen.

Ikonen, T., K. Ahlfors, R. Kempe, M. Ojala, and O. Ruottinen. 1999. Genetic parameters for the milk coagulation properties and prevalence of noncoagulating milk in Finnish dairy cows. J. Dairy Sci. 82:205-214.

Ikonen, T., A. Morri, A.-M. Tyrisevä, O. Ruottinen, and M. Ojala. 2004. Genetic and phenotypic correlations between milk coagulation properties, milk production traits, somatic cell count, casein content and pH of milk. J. Dairy Sci. 87:458-467.

Ikonen, T., M. Ojala, and E.-L. Syväoja. 1997. Effects of composite casein and $\beta$-lactoglobulin genotypes on renneting properties and composition of bovine milk by assuming an animal model. Agric. Food Sci. Finl. 6:283-294.

Johnson, M. E., C. M. Cen, and J. J. Jaeggi. 2001. Effect of rennet coagulation time on composition, yield, and quality of reduced-fat Cheddar cheese. J. Dairy Res. 84:1027-1033.

Kefford, B., M. P. Christian, B. J. Sutherland, J. J. Mayes, and C. Grainger. 1995. Seasonal influences on Cheddar cheese manufacture: Influence of diet quality and stage of lactation. J. Dairy Res. $62: 529-537$.

Kreuzer, M., A. M. von Siebenthal, A. Kaufmann, H. Rätzer, E. Jakob, and F. Sutter. 1996. Determination of the relative efficacy to enhance milk renneting properties of alterations in dietary energy, breed and stage of lactation. Milchwissenschaft 51:633-637.

Laporte, M.-F., R. Martel, and P. Paquin. 1998. The near-infrared optic probe for monitoring rennet coagulation in cow's milk. Int. Dairy J. 8:659-666.

Lindström, U. B., V. Antila, and J. Syväjärvi. 1984. A note on some genetic and nongenetic factors affecting clotting time of Ayrshire milk. Acta Agric. Scand. 34:349-355.

Macheboeuf, D., J.-B. Coulon, and P. D'Hour. 1993. Effect of breed, protein genetic variants and feeding on cows' milk coagulation properties. J. Dairy Res. 60:43-54.

Mariani, P., P. Serventi, and E. Fossa. 1997. Contenuto di caseina, varianti genetiche ed attitudine tecnologico casearia del latte delle vacche di razza Bruna nella produzione del formaggio grana. Allegato a La Razza Bruna Italiana 2:8-14.

Martin, B., J.-F. Chamba, J.-B. Coulon, and E. Perreard. 1997. Effect of milk chemical composition and clotting characteristics on chemical and sensory properties of Reblochon de Savoie cheese. J. Dairy Res. 64:157-162.

Ng-Kwai-Hang, K. F., I. Politis, R. I. Cue, and A. S. Marziali. 1989. Correlations between coagulation properties of milk and cheese yielding capacity and cheese composition. Can. Inst. Food Sci. Technol. 22:291-294.

O'Callaghan, D. J., C. P. O'Donnell, and F. A. Payne. 2002. Review of systems for monitoring curd setting during cheesemaking. Int. J. Dairy Technol. 55:65-74.

Ojala, M., A. M. Tyrisevä, and T. Ikonen. 2005. Genetic improvement of milk quality traits for cheese production. Pages 307-311 in Indicators of Milk and Beef Quality. J. F. Hocquette and S. Gigli, ed. Wageningen Academic Publishers, Wageningen, the Netherlands.

Raftery, A. E., and S. M. Lewis. 1992. How many iterations in the Gibbs Sampler? Pages 763-774 in Bayesian Statistics IV. J. M. Bernardo, J. O. Berger, A. P. Dawid, and A. F. M. Smith, ed. Oxford Univ. Press, New York, NY.

Rutten, M. J., P. Bijma, J. A. Woolliams, and J. A. M. Van Arendonk. 2002. SelAction: Software to predict selection response and rate of inbreeding in livestock breeding programs. J. Hered. 93:456-458.

Tyrisevä, A. M., T. Vahlsten, O. Ruottinen, and M. Ojala. 2004 Noncoagulation of milk in Finnish Ayrshire and Holstein-Friesian cows and effect of herds on milk coagulation ability. J. Dairy Sci. 87:3958-3966.

von Oloffs, K., H. Schulte-Coerne, K. Pabst, and H. O. Gravert. 1992. Die Bedeutung der Proteinvarianten für genetische Unterschiede in der Käsereitauglichkeit der Milch. (The relevance of protein variants to genetic differences in cheese making properties in milk). Zuchtungskunde 64:20-26.

Williams, P. 2003. Near-infrared technology getting the best out of light. Page 109 in A Short Course in the Practical Implementation of Near Infrared Spectroscopy for the User. 1.1 ed. PDKProjects Inc., Nanaimo, Canada.

Zannoni, M., and S. Annibaldi. 1981. Standardization of the renneting ability of milk by Formagraph. Sci. Tecn. Latt. Cas. 32:79-94. 